\title{
Pneumonia caused by crizotinib: case report and review of literature
}

\author{
Xiaoli Gou ${ }^{1}$, Cheng Yuan ${ }^{2}$, Yuju Bai ${ }^{1}$, Lei Shi ${ }^{1}$, Shiyun Xing ${ }^{1}, \mathrm{Hu} \mathrm{Ma}^{1}$ \\ ${ }^{1}$ Department of Oncology, The Affiliated Hospital of Zunyi Medical University, Zunyi, China; ${ }^{2}$ The First People's Hospital of Zunyi (The Third \\ Affiliated Hospital of Zunyi Medical University), Zunyi, China \\ Correspondence to: Cheng Yuan. The First People's Hospital of Zunyi (The Third Affiliated Hospital of Zunyi Medical University), Zunyi, China. \\ Email: 642509819@qq.com; Hu Ma. Department of Oncology, The Affiliated Hospital of Zunyi Medical University, 1 Dalian Road, Zunyi, China. \\ Email: mahu2020@163.com.
}

\begin{abstract}
Crizotinib is the first-line drug for non-small cell lung cancer (NSCLC) patients who display anaplastic lymphoma kinase $(A L K)$ rearrangement. With $60 \%$ overall response rate, crizotinib significantly prolongs median progression-free survival (ranged 8-10 months) of ALK rearrangement NSCLC patients. However, there are some adverse events from crizotinib, including diarrhea, weakness and nausea. Here, we describe a 47 years old woman with ALK-rearranged NSCLC who developed interstitial pneumonia (IP) induced by crizotinib. A female patient was diagnosed as the left lower lobe adenocarcinoma stage IV (T4N2M1, pleural metastasis) via lung biopsy and was detected wild-type EGFR and 18\% ALK gene rearrangement from paraffin section. However, after going through 7 cycles of chemotherapy, she rejected chemotherapy because side effect and still experienced progression of the disease. Subsequently, crizotinib was prescribed as a targeted therapy. After 32 days, visible reduction in size was observed on the pulmonary mass and metastases found in brain and liver, but the patient presented drug-induced level 4 interstitial pneumonia. In a nutshell, the curative effect of crizotinib is worthy of note, but clinicians should also weigh the advantages and disadvantages, prior its usage.
\end{abstract}

Keywords: Non-small-cell lung cancer (NSCLC); anaplastic lymphoma kinase (ALK); crizotinib; pneumonia; case report

Submitted Oct 26, 2019. Accepted for publication Aug 19, 2020.

doi: $10.21037 / \mathrm{apm}-19-420$

View this article at: http://dx.doi.org/10.21037/apm-19-420

\section{Introduction}

The recent discovery of driver mutation, such as epidermal growth factor receptor mutations and anaplastic lymphoma kinase (ALK) rearrangements, has dramatically changed the treatment of non-small cell lung cancer (NSCLC). With an occurrence rate of $3-10 \%$, the significance of $A L K$ rearrangement in NSCLC is notable (1). Crizotinib is recommended for ALK positive NSCLC patients by the National Comprehensive Cancer Network (NCCN) Guideline Version 3. 2018, because of $60 \%$ overall response rate (ORR) and median progression-free survival (PFS) time of 8-10 months (2). However, some common adverse events are observed, such as nausea, diarrhea and weakness (3).
Since there have only been a few cases applying this drug, fewer side effects have been reported. An ALK-rearranged patient was administered with Crizotinib as a targeted therapy to check the efficacy levels. The efficacy was notably positive with a small glitch-a rare drug-induced level 4 interstitial pneumonia contracted the patient (4). We present the following case in accordance with the CARE Reporting Checklist (5) (available at http://dx.doi. org/10.21037/apm-19-420).

\section{Case presentation}

On November 27, 2012, a 47-year-old female was diagnosed 
November 27, 2012, a 47-year-old female was diagnosed as the left lower lobe adenocarcinoma stage IV
August 29, 2013, molecular target treatment was initiated and the patient was given oral Crizotinib, with a dose of $250 \mathrm{mg}$, twice a day
The patient was therefore administered with dexamethasone $10 \mathrm{mg}$ plus cefuroxime $2.0 \mathrm{mg}$ twice a day and oxygen inhalation

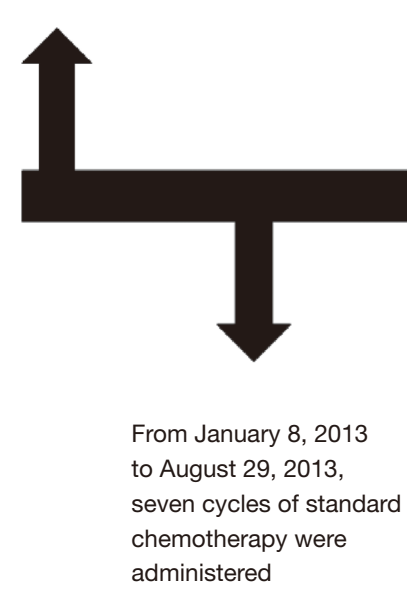

administered
September 29th, 2013, Crizotinib also led to some side effects. Crizotinibinduced level 4 interstitial pneumonia

Figure 1 Timeline of the patient's therapy.

as the left lower lobe adenocarcinoma stage IV (T4N2M1, pleural metastasis) via lung biopsy and was detected wildtype EGFR and $18 \% A L K$ gene rearrangement from paraffin section. Subsequently, the patient selected standard chemotherapy as adjuvant treatment considering the economic condition. Hence, from January 8, 2013 to August 29, 2013, seven cycles of standard chemotherapy were administered including three cycles PC regimen (paclitaxel, $150 \mathrm{mg} / \mathrm{m}^{2}$ plus cisplatin $75 \mathrm{mg} / \mathrm{m}^{2}$ ), two cycles PP regimen (pemetrexed, $500 \mathrm{mg} / \mathrm{m}^{2}$ plus cisplatin $75 \mathrm{mg} / \mathrm{m}^{2}$ ), one cycle DP regimen (docetaxel, $75 \mathrm{mg} / \mathrm{m}^{2}$ plus cisplatin $75 \mathrm{mg} / \mathrm{m}^{2}$ ) and one cycle NP regimen (vinorelbine $30 \mathrm{mg} / \mathrm{m}^{2}$ plus cisplatin $75 \mathrm{mg} / \mathrm{m}^{2}$ ) along with Endostar (Figure 1).

Because of the aggravated side effects, the patient refused to take systemic chemotherapy. However, the primary lesion of left lung still existed and metastases developed in brain (Figure $2 A$ ) from magnetic resonance imaging (MRI) and in lungs and liver (Figure 2B) from CT scan. Hence, crizotinib targeted drug therapy was recommended. Simultaneously, the patient was diagnosed with lower left lung adenocarcinoma, stage IV, along with bilateral lung, pleura, brain and liver metastases (Figure 2).

Molecular target treatment was initiated on August 29, 2013 and the patient was given oral Crizotinib, with a dose of $250 \mathrm{mg}$, twice a day. Also, whole brain radiotherapy (WBRT) alongside in-field boost (6) commenced on August 29, 2013. The repeated MRI reported that the metastases of cerebrum and cerebellum have markedly decreased in size (Figure 3A).

However, Crizotinib also led to some side effects, though minor ones. Although a chest CT scan showed that the tumors on the left lower lobe and hepatic had reduced significantly, along with the mediastinal lymph nodes and hilus pulmonis lymph node (Figure $3 B, C$ ), the patient experienced a low-grade fever, chest tightness, shortness of breath and Karnofsky performance status (KPS) (7) rating falling to 60 point. The lung exudative lesions had increased in size (Figure 4A). Considering the symptoms like wet rales and shortness of breath, the history of Crizotinib administration, imaging findings and lack of bacterial growth found on multiple sputum cultures, a diagnosis of Crizotinib-induced level 4 interstitial pneumonia (Common Terminology Criteria for Adverse Events, v.3.0) was performed. The patient was therefore administered with dexamethasone $10 \mathrm{mg}$ plus cefuroxime $2.0 \mathrm{mg}$ twice a day and oxygen inhalation. Quick medical follow-up and treatment could reduce the chest tightness and shortness of breath. Significantly, a rise on KPS score was witnessed, whereby improving the symptoms. CT scan showed that the pulmonary exudative lesion area disappeared in contrast with the results of the previous scan lesion area (Figure 4B,C). Finally, on October 14, 2013, the patient was discharged from the hospital accounting for the signs of recovery. And continuous treatment with lower dosages was 

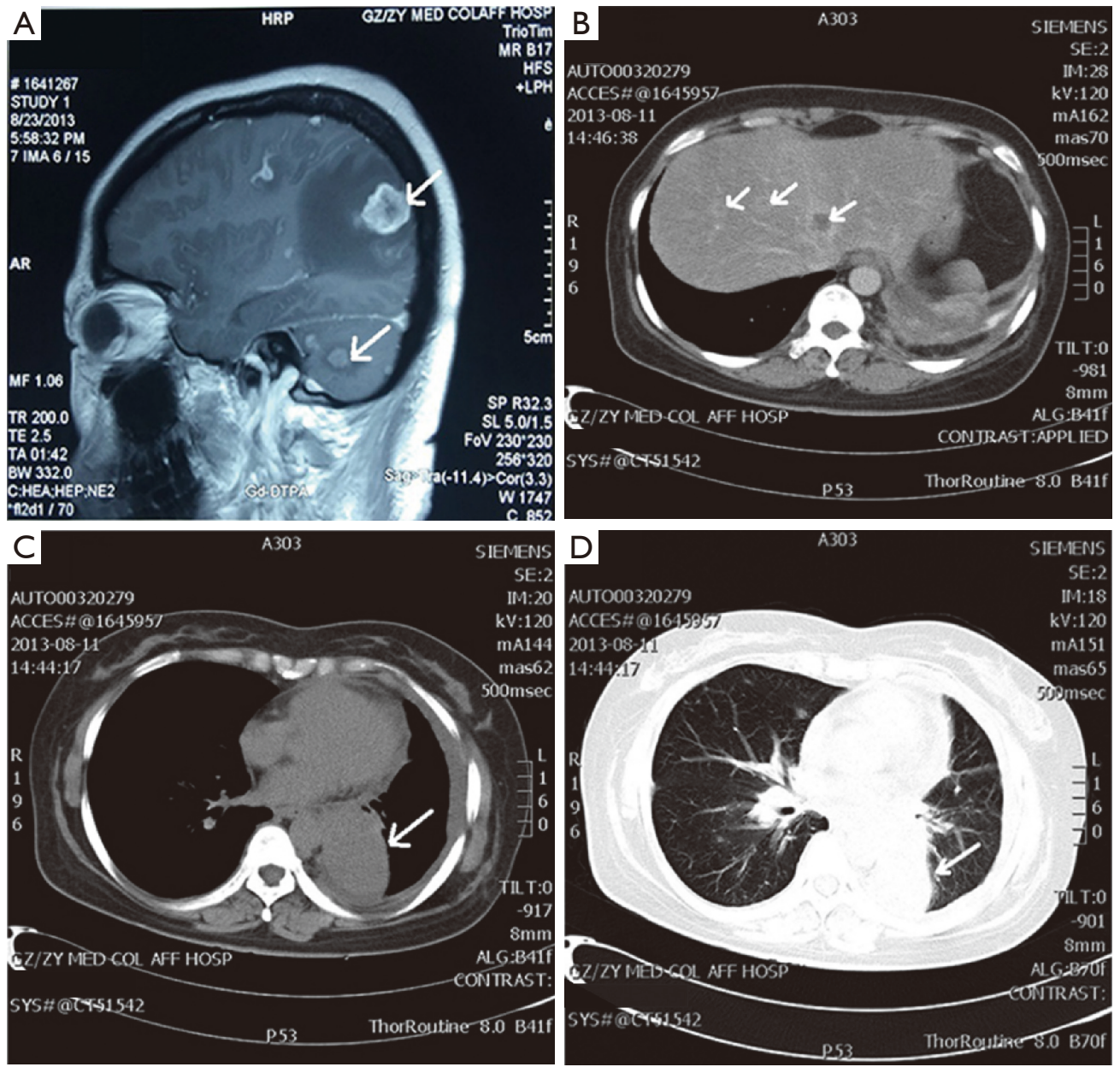

Figure 2 Diagnoses of lower left lung adenocarcinoma, stage IV, along with bilateral lung, pleura, brain and liver metastases. (A) Forebrain metastases before the treatment with crizotinib, larger lesion is $2.8 \mathrm{~cm}$, and smaller lesion is $1.5 \mathrm{~cm}$ in size (captured on 23rd August, 2013); (B) the hepatic metastases before the crizotinib treatment, 5 lesions are present (captured on 11 ${ }^{\text {th }}$, August, 2013); (C) the fore mediastinal window before the crizotinib treatment (captured on $11^{\text {th }}$, August, 2013); (D) fore lung window before the crizotinib treatment. The lesion is $6.8 \mathrm{~cm}$ (captured on $11^{\text {th }}$, August, 2013).

still needed.

The study was approved by institutional Ethics Committee of the Affiliated Hospital of Zunyi Medical University. Written informed consent was obtained from the patient for publication of this case report and any accompanying images.

\section{Discussion}

Molecular markers like ALK rearrangement and individual targeted treatment like crizotinib have become a hot topic of research (8). Inhibiting the kinase activity of fusion protein which is the result of the chromosomal rearrangement, crizotinib is widely used for lung cancer caused by fused $A L K$ and $E M L 4$ gene. At the annual meeting of the American Society of Clinical Oncology, the results of clinical phase II trial (profile A8081005) using crizotinib to treat ALK-positive NSCLC patients, revealed that out of 133 patients, $51.1 \%$ showed curative results and $85 \%$ and $73.7 \%$ were the $6-$ and 12 -week disease control rates, respectively (9). In 2012, the European Society of Medical Oncology updated the research result of the A8081005 trial (10).

Considering the adverse effects of crizotinib, visual abnormalities, nervous lesions, heart abnormalities, kidney injury and QT interval extension are the most common 



Figure $3 \mathrm{MRI}$ and CT image. (A) After the 24 days of crizotinib therapy and whole brain radiotherapy, the larger lesions reduced to $1 \mathrm{~cm}$, and smaller lesions disappeared completely (captured on 22nd September, 2013); (B) lesion in mediastinal window of the chest was significantly reduced and after taking 32 days disappeared completely (captured on 29th September, 2013); (C) the hepatic lesions were significantly reduced after 32 days of taking the crizotinib, three hepatic lesions disappeared, the larger lesion reduced from 2 to $1 \mathrm{~cm}$, the smaller lesion reduced from 1 to $0.5 \mathrm{~cm}$ (captured on 29th, September, 2013).
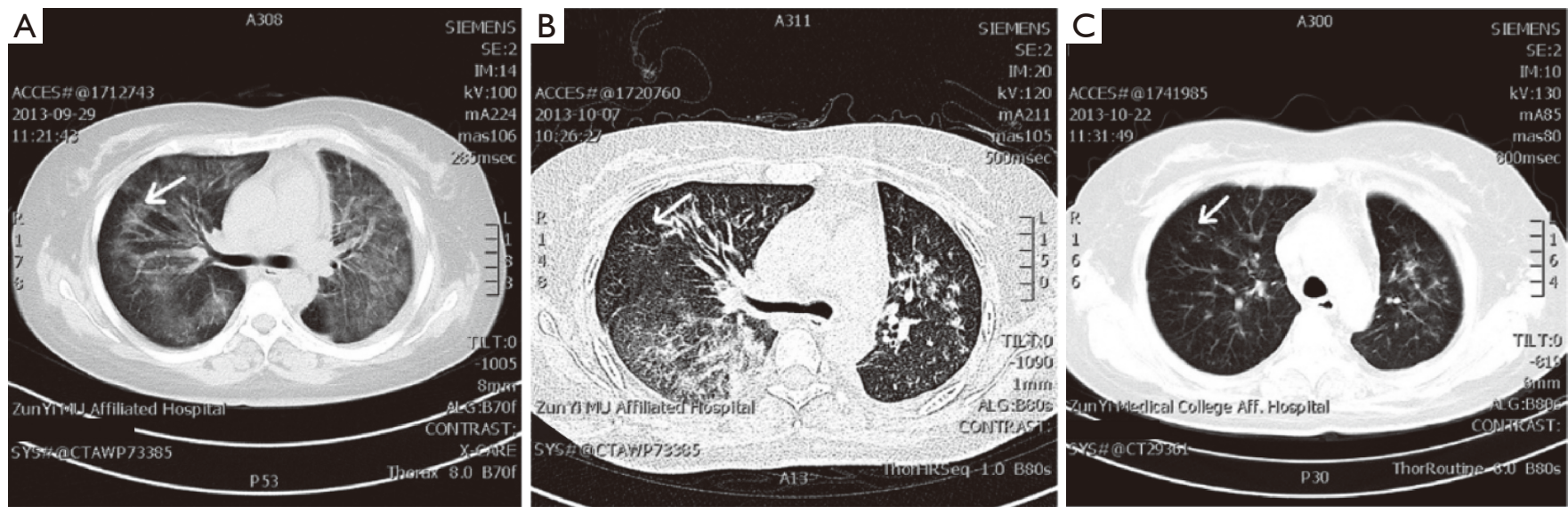

Figure 4 CT image. (A) The occurrence of pneumonia after taking the crizotinib for 32 days (captured on 29th, September, 2013); (B) the state after the crizotinib was suspended in hormone therapy in 8 days, lesion area is reduced by $1 / 5$ (captured on 7 th October, 2013); (C) the state after the crizotinib was suspended in hormone therapy in 23 days, lesion area is significantly reduced by $2 / 3$ (hormone is reducing) (captured on $22^{\text {nd }}$, October, 2013).

ones (11). By September 2012, according to the updated safety data researched in the A8081001, A8081005 and A8081007 trials, $0.5 \%$ of NSCLC patients developed drugrelated hepatotoxicity and $2 \%(22 / 1,354)$ of the patients displayed treatment-related interstitial lung disease/ pneumonia (12), in which 14 cases $(1 \%)$ were between 3 and 5 levels, suggesting serious condition (13). Watanabe et al. presented a case of crizotinib-induced ILD. Although the report also showed a patient with EML4-ALK positive
NSCLC, IP is preexisting (14). Whereas, in our report, the patient, which had no medical history of IP and no any symptoms associated with IP before crizotinib treatment, presented wet rale, shortness of breath, exudative imaging after using it. To reduce chest distress and anhelation, an active glucocorticoid treatment needs to be followed. The dose, adjusted according to prescription, can be reduced slowly over time. It's a case drawing our attention that although the restoring effect of crizotinib on $A L K$ gene 
rearrangement benefits to rearranged-ALK NSCLC patients, its side effects and toxicity should not be ignored too. Also, the drugs should be used on right time and in the right manner in order to display maximal efficiency.

This is a single case and spontaneous regressionthough rare-cannot be ruled out. However, these are often associated with immunologic responses, a possible positive contribution of crizotinib to tumor control in NSCLC seems worthwhile to be further investigated.

\section{Acknowledgments}

Funding: This research was supported by Natural Science Foundation of China (NSFC) (81360351), The Department of Science and Technology of Guizhou Province (grant No. QianKe He SY [2013] 3003), High-Level Innovative Talents Cultivation Program of Guizhou Province, Start-Up Fund for Doctor of Zunyi Medical University (No. 2012), The Social Practice Program for Postgraduate of Zunyi Medical University (grant No. zyyjs2015004), and Guizhou Science and Technology Foundation Project (Guizhou Science and Technology LH word [2014] 7578).

\section{Footnote}

Reporting Checklist: The authors have completed the CARE Reporting Checklist. Available at http://dx.doi. org/10.21037/apm-19-420

Conflicts of Interest: All authors have completed the ICMJE uniform disclosure form (available at http://dx.doi. org/10.21037/apm-19-420). The authors have no conflicts of interest to declare.

Ethical Statement: The authors are accountable for all aspects of the work in ensuring that questions related to the accuracy or integrity of any part of the work are appropriately investigated and resolved. The study was approved by institutional Ethics Committee of the Affiliated Hospital of Zunyi Medical University. Written informed consent was obtained from the patient for publication of this case report and any accompanying images. The study was conducted in accordance with the Declaration of Helsinki (as revised in 2013).

Open Access Statement: This is an Open Access article distributed in accordance with the Creative Commons Attribution-NonCommercial-NoDerivs 4.0 International
License (CC BY-NC-ND 4.0), which permits the noncommercial replication and distribution of the article with the strict proviso that no changes or edits are made and the original work is properly cited (including links to both the formal publication through the relevant DOI and the license). See: https://creativecommons.org/licenses/by-nc-nd/4.0/.

\section{References}

1. Cufer T, Ovcaricek T, O'Brien ME. Systemic therapy of advanced non-small cell lung cancer: major-developments of the last 5-years. Eur J Cancer 2013;49:1216-25.

2. Wu J, Savooji J, Liu D. Second-and third-generation ALK inhibitors for non-small cell lung cancer. J Hematol Oncol 2016;9:19.

3. Shaw AT, Ou SH, Bang YJ, et al. Crizotinib in ROS1rearranged non-small-cell lung cancer. $\mathrm{N}$ Engl J Med 2014;371:1963-71.

4. Murga-Zamalloa C, Lim MS. Alk-driven tumors and targeted therapy: focus on crizotinib. Pharmgenomics Pers Med 2014;7:87-94.

5. Riley DS, Barber MS, Kienle GS, et al. CARE 2013 Explanations and Elaborations: Reporting Guidelines for Case Reports. J Clin Epidemiol 2017;89:218-35.

6. Zhou L, Liu J, Xue J, et al. Whole brain radiotherapy plus simultaneous in-field boost with image guided intensitymodulated radiotherapy for brain metastases of non-small cell lung cancer. Radiat Oncol 2014;9:117.

7. Baka S, Ashcroft L, Anderson H, et al. Randomized Phase II Study of Two Gemcitabine Schedules for Patients With Impaired Performance Status (Karnofsky performance status $<=70$ ) and Advanced Non-Small-Cell Lung Cancer. J Clin Oncol 2005;23:2136-44.

8. Shaw AT, Kim TM, Crinò L, et al. Ceritinib versus chemotherapy in patients with alk-rearranged non-smallcell lung cancer previously given chemotherapy and crizotinib (ascend-5): a randomised, controlled, open-label, phase 3 trial. Lancet Oncol 2017;18:874-86.

9. Crino L, Kim D, Riely GJ. Initial phase ii results with crizotinib in advanced alk-positive non-small cell lung cancer (NSCLC): profile 1005. J Clin Oncol 2011;29:7514.

10. Kim DW, Ahn MJ, Shi Y, et al. Results of a global phase II study with crizotinib in advanced ALK-positive nonsmall cell lung cancer (NSCLC). Meeting of the JapaneseSociety-Of-Medical-Oncology 2012;30:32-33.

11. Kwak EL, Bang YJ, Camidge DR, et al. Anaplastic lymphoma kinase inhibition in non-small-cell lung cancer. N Engl J Med 2010;363:1693-703. 
12. Shaw AT, Yeap BY, Solomon BJ, et al. Effect of crizotinib on overall survival in patients with advanced non-smallcell lung cancer harbouring alk gene rearrangement: a retrospective analysis. Lancet Oncol 2011;12:1004-12.

13. Paik PK, Arcila ME, Fara M, et al. Clinical characteristics of patients with lung adenocarcinomas harboring BRAF

Cite this article as: Gou X, Yuan C, Bai Y, Shi L, Xing S, Ma H. Pneumonia caused by crizotinib: a case report and review of literature. Ann Palliat Med 2021;10(4):4932-4937. doi: 10.21037/ apm-19-420 mutations. J Clin Oncol 2011;29:2046-51.

14. Watanabe N, Nakahara Y, Taniguchi H, et al. Crizotinib-induced acute interstitial lung disease in a patient with EML4-ALK positive non-small cell lung cancer and chronic interstitial pneumonia. Acta Oncol 2014;53:158-60. 